Barachini, Teresinha (Tetê).

Profesora Adjunta e Investigadora de la Universidad Federal de Río Grande del Sul, Departamento de Artes Visuales y Artista Visual.

\title{
Un objeto entre la exclusión y la protección.
}

\section{An object between the exclusion and the protection.}

\author{
TIPO DE TRABAJO: \\ Comunicación virtual. \\ PALABRAS CLAVE: \\ Muro de Mauá, objeto-muro, paisaje, territorio, urbano. \\ KEY WORDS: \\ Wall of Mauá, object-wall, landscape, territory, urban.
}

RESUMEN.

Los muros son objetos fronterizos construidos para proteger territorios y practicar exclusiones y separaciones. Para este texto traigo los muros urbanos de Brasil y más específicamente, el Muro de la Av. Mauá, localizado a la orilla del área portuaria de la ciudad de Porto Alegre/Brasil. Su interferencia en el paisaje es absolutamente contundente, aunque muchas veces, el mismo no sea ni siquiera notado, por aquellos que conviven diariamente con él. Ambiguo en su existencia, el Muro resiste a los debates entre aquellos que lo defienden como necesario y los que lo consideran un estorbo reclamando su retirada. A fin de entenderlo y resignificarlo, desde 2015, un colectivo de artistas investigadores viene estableciendo diferentes estrategias poéticas de aproximación y coparticipación con el Muro y su entorno, generando nuevas interrelaciones entre este protagonista y la ciudad.Se realizaron una serie de deambulaciones propositivas y colectivas, tales como: Visita Imprecisa (2015), Turista Puede (2015) y Espiada (2016).

\section{ABSTRACT.}

Walls are boundary objects built to protect land, as well as exclude and separate. This article discusses Brazil's urban walls, specifically the wall along Avenue Mauá, which borders the port of the city of Porto Alegre, Brazil. Despite its blatant interference with the landscape, it is often barely noticed by those who live with it on a daily basis. Ambiguous in its existence, The Wall resists debates between those who defend it as necessary and others who consider it an eyesore and call for its demolition. In order to understand and reevaluate the structure, since 2015 a group of artist-researchers has been establishing different poetic strategies to share and approximate The Wall with its surroundings, generating new interrelationships between this protagonist and the city. A series of collective walks led by artists were carried out, including Visita Imprecisa (Imprecise Visit) (2015), Turista Puede (Tourists Can) (2015) and Espiada (Peeking) (2016).

\section{CONTENIDO.}

\section{MUROS A UN LADO Y AL OTRO}

Tendemos a notar a las ciudades contemporáneas con sus cartografías descentralizadas, donde los espacios reconocidamente como, centro y periferia o, dentro y fuera parecen no tener más sentido. Sin embargo,el cotidiano nos muestra que los límites materiales o 


\author{
Barachini, Teresinha (Tetê). \\ Un objeto entre la exclusión y la protección. \\ III CONGRESO INTERNACIONAL DE INVESTIGACIÓN EN ARTES VISUALES :: ANIAV 2017 :: GLOCAL [codificar, mediar, transformar, vivir] \\ http://dx.doi.org/10.4995/ANIAV.2017.5837
}

inmateriales responsables por las demarcaciones de fronteras ,o incluso, responsables por los sistemas de protección a territorios políticos o socio-económicos, no sólo se mantienen a través de viejas y nuevas configuraciones persuasivas,sino que en este momento son retomados en casi todos los países, teniendo como uno de sus protagonistas a los muros.

Existe un cierto espanto en vivenciar las repercuciones y la celebración que el mundo sintió luego de la caída del muro de Berlín y, contrariamente tomar conciencia de la construcción y la ampliación del muro de Cisjordania y el mantenimiento del muro ubicado en la frontera entre España y Marruecos, o aún, presenciar recientemente la campaña política de Donald Trump que fomentó la idea de la construcción de un muro en toda la extensión de la frontera de EE.UU. con México. En medio a estas y otras perplejidades, traigo para este texto muros urbanos de Brasil y, más específicamente, un muro construido entre un lago y una ciudad.

En Río de Janeiro/Brasil, por ejemplo,la villa miseria "Rocinha" fue cercada con $10 \mathrm{~km}$ de muro de 3 metros de altura a fin de impedir su crecimento y, de este modo, proteger la Selva Atlántica en los montes cariocas. Carlos Hardt (2009) recuerda que "en una ciudad, cuando se construye un muro, un acto agresivo, [él] es una muestra de incapacidad" política y urbanística, porque "nadie va mirar y decir: Dios mío que hermoso!"

Las ciudades brasileñas están repletas de enormes muros de una heterogeneidad y estructura impresionantes, aún así, según Zarankin (2012, p-19-22) estos permanecen imperceptibles en el cotidiano y llegan a ser considerados elementos normales de los paisajes urbanos brasileños, inclusive, deseados como sinónimo de estatus social y económico. Este absurdo es

captado por ejemplo, según Teresa Caldeira (2011), por el artista catalán Muntadas con su obra Aphaville y otros (2011), lo cual pone en evidencia un barrio cerrado en la ciudad de San Paulo cercado con sus muros segregadores. En este y en otros sitios la elite brasileña levanta sus fortalezas creando escenarios que naturalizan la desigualdad social y la separación.

"Los muros que cercan Aphaville son muy peculiares. Como muestra [la obra] Aphaville y otros, ellos son absurdamente largos. Se extienden por más de 10 quilómetros y es posible conducir a su lado por mucho tiempo. Una de las cosas más impresionantes sobre los muros de Aphaville es que son admirablemente blancos. Ni siquiera los muros más fortificados del mundo contemporáneo, como el Muro de Palestina o el muro de la frontera norteamericana con México, escaparon del grafito, una intervención que transforma a los muros en polos de vergüenza y debate. Sin embargo, los muros de Aphaville no poseen grafito. Esta limpieza es tan sólo, cierta indicación de la fuerza del aparato de seguridad del cual ,el muro es solamente una parte." (CALDEIRA, 2011, p. 233)

Adoptado, también como solución, un muro de 3 metros de altura con casi 3km de extensión es construido entre el muelle y la ciudad de Porto Alegre/Brasil, limitando los desplazamientos corporales de aproximación a la orilla del lago Guaíba, en una postura ambigua entre el separar y proteger a la ciudad de sus aguas y de sus islas, negando en algún sentido su vocación de puerto. Este muro de la Mauá, muchas veces llamado de "Muro de la Vergüenza", con el intuito de proteger a la ciudad de las aguas de inundaciones futuras, se tornó una realidad material en la década del 70, al ser construido. Firmó, así, entre lo urbano y el lago, una espesura longitudinal permanente: el "Muro de Mauá".

Este objeto - el 'muro', constituido de textura, color e historia, crea una enorme interferencia en el paisaje, transformándola, y modificando los hábitos de los habitantes de la ciudad y de aquellos que por allí pasan, dividiendo la memoria entre antes y después del muro. Su inevitable materialidad nos induce a pensar sobre sus significados de protección y distanciamiento, ni siempre tan explícitos cuando en su presencia,pero innegablemente generados a partir de la absorción de su existencia, sea por la mirada indagativa o por la aproximación corporal en su perímetro. 


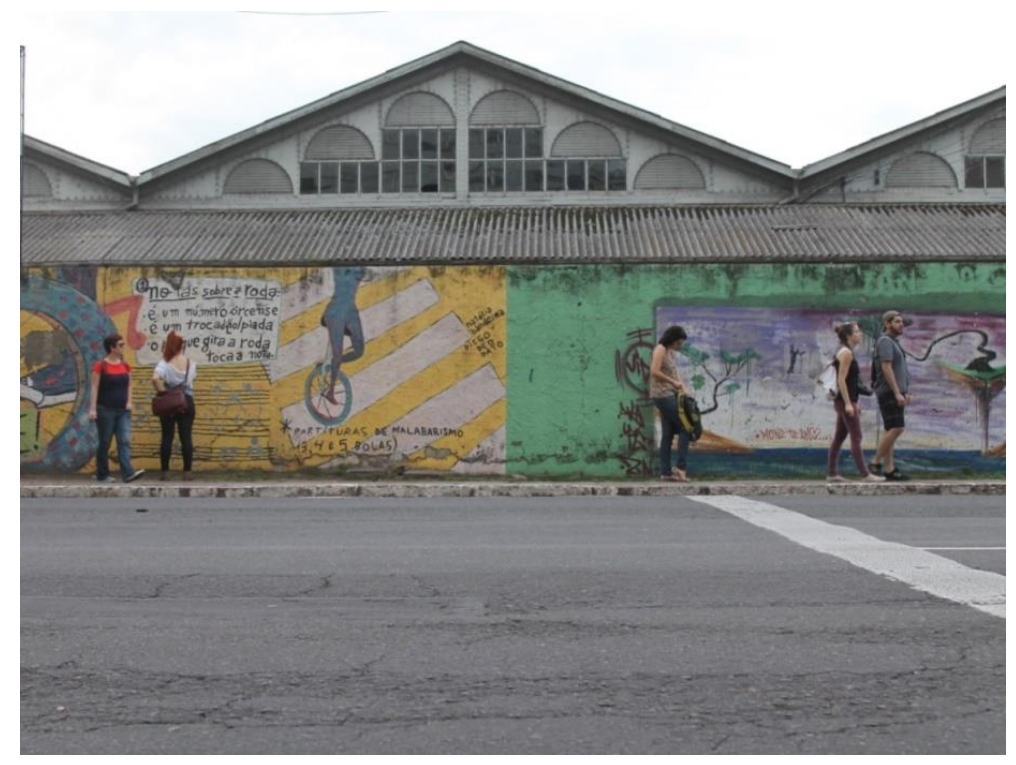

Figura 1- Visita Imprecisa, 2015. Fecha: 23/05/2015. Lugar: Muro de la Av. Mauá, en Porto Alegre, RS/Brasil. De izquierda a derecha: Manoela Cavalinho, Alice Brauwers, Liziane Minuzzo,Bruna Gazzi y Thiago Trindade Foto: Deni Corsino

\section{DE CERCA, DE LEJOS, DE ARRIBA}

Este extenso objeto, el Muro de Mauá, que esconde el paisaje formado por la orilla y por las aguas del Lago Guaíba, llevó a un grupo de artistas el 23 de mayo de 2015 a hacer su primera acción colectiva, una Visita Imprecisa ${ }^{1}$ (Fig. 1). Decidieron por la visita como una 'experiencia Dadaísta', o sea, una excursión a un lugar banal de la ciudad, a fin de activarlo. Y, aunque, fuese absolutamente imposible el reconocimiento visual de su totalidad, la visita en cierto sentido potencializó aquel objeto urbano longitudinal como posible lugar poético para los artistas envueltos en la acción.

A medida que estos aprendían el espacio formado por aquella barrera física y visual, sentían el impacto de dos velocidades, una era el trayecto a pie, lento y absorvente del entorno próximo y la otra era la velocidad realizada por los vehículos que recorrían la Av. Mauá, recordando a todos que la ciudad estaba allí. El lado que pertenece a la avenida, o sea, su lado de 'dentro' de la ciudad o su lado 'externo' en relación al muelle, antes aparentemente neutro, a partir de la Visita Imprecisa, se impone para el grupo como un objeto limitador del 'otro' paisaje, es decir, de las imágenes que serían posibles obtener si él no estuviese allí. Por otro lado, al mirar para el objeto-muro, lo que se torna accesible es un paisaje plano resultante de superficies cubiertas de forma irregular por grafismos y rajaduras que intentan, de cierta foma, devolver a la ciudad paisajes robados o imaginados.

Del otro lado del muro, del lado del área del muelle, el cual no es accesible a la población local, el muro se pone gris acero verdoso, con señalizaciones codificadas y, de vez en cuando, puede observarse césped que insiste en crecer entre las rajaduras del muro, así como, árboles nativos de un lado y palmeras de otro. Vivenciar los dos lados de este muro, es probar la diversidad idiosincrática de la población local en relación al espacio allí marcado, cortado, delimitado y codificado. Estos espacios aparentemente públicos - los dos lados del muro -, se cierran y se vuelven locales de anticonvivencia, representando áreas de violencia y exclusión. Repitiendo una práctica urbana de otras ciudades brasileñas, donde los lugares públicos tienen, según Canton,

"su uso abandonado por el miedo o dejado a la deriva, a la sombra de la soledad urbana. El lugar público, que sería el lugar de todos, pasa al status de lugar de nadie. Es abandonado, maltrado, ensuciado, ignorado, transformado en chatarra. El deseo de los artistas contemporáneos de dialogar con los espacios públicos de la ciudad como forma de expandir sus poéticas queda cada vez más amenazado y se vuelve un contrapunto a la amenaza de la violencia, al miedo, al aislamiento propuesto por una arquitectura de muros, rejas y vigilancia." (Canton, 2009, p.42-43)

\footnotetext{
${ }^{1}$ Ver mayores informaciones en: http://www.om-lab.com.br
} 


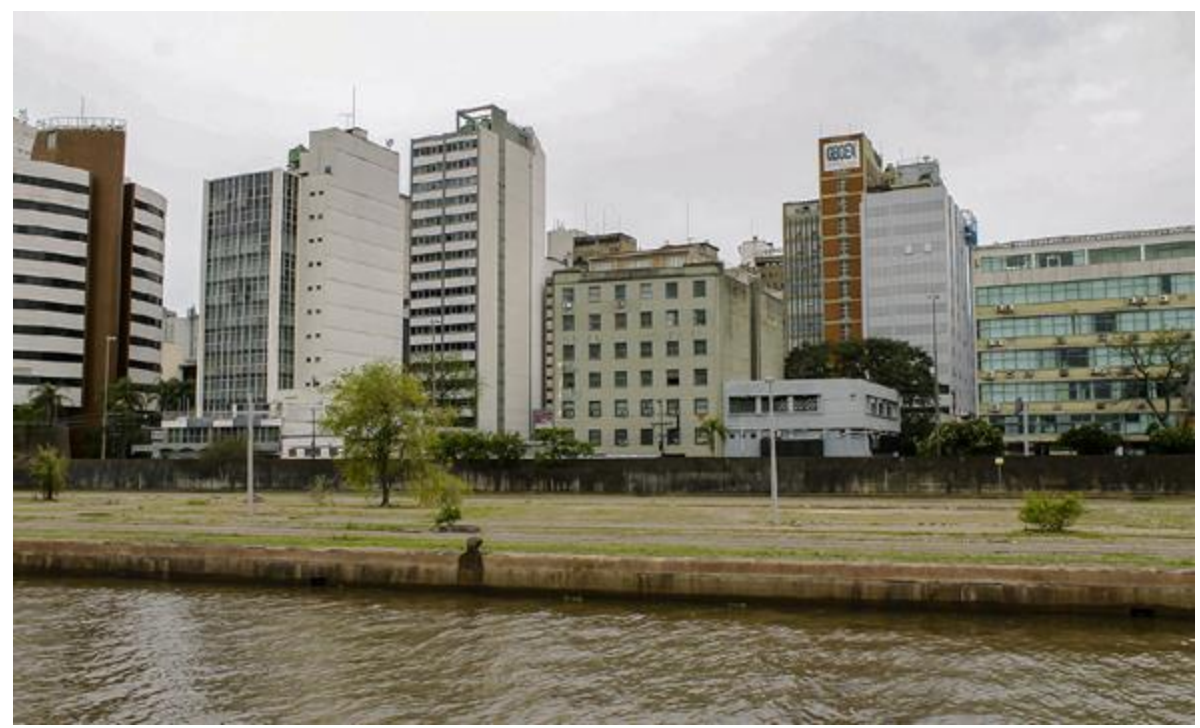

Figura 2- Turista Puede, 2015. Fecha: nov/2015. Lugar: Lago Guaiba - RS /Brasil. Foto: Thiago Trindade

Además de las deambulaciones y visitas próximas a sus superficies, los artistas realizaron la acción Turista Puede (2015) ${ }^{2}$ (Fig. 2) al embarcar en el Cisne Blanco ${ }^{3}$, y así, pudieron acceder visualmente el 'muro' costeando parcialmente el muelle, pues el acceso que no está permitido al residente, es perniciosamente concedido al turista. Tristemente se percibe que el territorio líquido y el paisaje son de uso del otro, del extranjero, del turista.

Sobre la superficie líquida y expandida del Lago Guaíba, situados entonces en un barco, "un pedazo de espacio flotante, un lugar sin lugar" (Foucault, 2009, p.421), en la posición en que está permitida al turista apreciar el paisaje, los artistas avistaron el 'muro' feo y bruto y redescubrieron la ciudad de Porto Alegre, con sus capas y sus opacidades. Por sobre las aguas del lago, el 'muro' se colocaba distante y visualmente segmentado entre los vanos de los almacenes. Se reafirmaba definitivamente invisible ante la verticalidad del área urbana que este se propone proteger. Solitario en su extensión, se reconfiguraba en un espacio aislado, abandonado en su propio olvido, un lugar sin pertenecimientos, sin accesos, tal como el actual muelle de la ciudad de Porto Alegre-RS/Brasil. En la distancia, el 'muro' desaparece, sobran sólo manchas de las capas sobrepuestas de la ciudad y del puerto, el paisaje divide lo vertical y lo horizontal en solamente una escena, y el tiempo elástico en su duración se ausenta, sobra la memoria de un 'muro' que los recibirá al desembarcar en Porto Alegre.

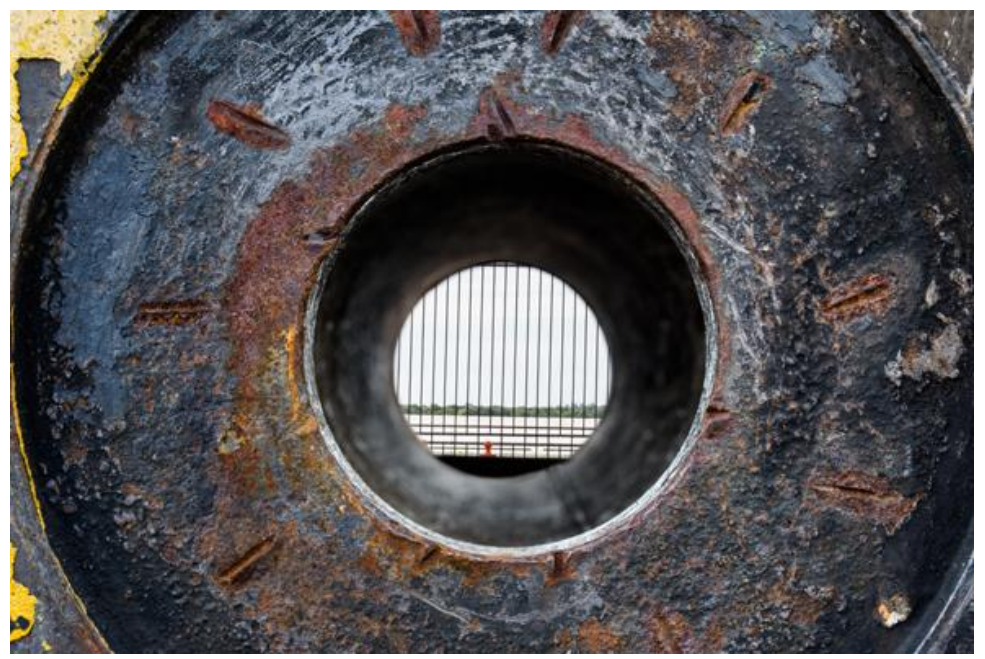

Figura 3- Espiada, 2016. Lugar: Muro de la Av. Mauá, en Porto Alegre, RS/Brasil. Foto: Filipe Conte

\footnotetext{
${ }^{2}$ Turista Puede (2015) fue realizado por los artistas-investigadores: Deni Corsino, Filipe Conde, Manoela Cavalinho, Tetê Barachini, Thiago Trindade. Ver mayores informações en: http://www.om-lab.com.br

${ }^{3}$ El barco Cisne Blanco realiza paseos turísticos por las islas próximas a la ciudad de Porto Alegre.
} 


\author{
Barachini, Teresinha (Tetê). \\ Un objeto entre la exclusión y la protección. \\ III CONGRESO INTERNACIONAL DE INVESTIGACIÓN EN ARTES VISUALES :: ANIAV 2017 :: GLOCAL [codificar, mediar, transformar, vivir] \\ http://dx.doi.org/10.4995/ANIAV.2017.5837
}

La ciudad de Porto Alegre-RS/Brasil mira para el Muro de Mauá como parte de un paisaje urbano, no lo penetra, no lo atraviesa, porque no lo ve. Para los que frequentan la ciudad y lo ven, este los lleva a mirar tanto para su integridad material, como los invita a jugar de elevar sus miradas hasta su borde y, desde arriba, intentar mirar el deseo oculto de rescatar una ciudad que se propuso ser otra antes de la construcción de este objeto longitudinal.

Luego de una serie de incursiones al muro entre 2015 y 2016, los artistas resolvieron hacer una invitación abierta a la comunidad local para que vivenciasen un acercamiento no sólo al muro,sino también a los paisajes por él negados. Y, con esta proposición, los artistas realizaron la acción Espiada (2016) (Fig. 4). Esta acción propuso una serie de aproximaciones de redescubrimiento de aquel lugar, tales como: intentar mirar el entorno utilizando "gafas-ciego" de la artista Bruna Gazzi, intentar encontrar y ver los pequeños paisajes escondidos a través de los huecos (Fig. 3) existentes en el muro o adueñarse de imágenes reflejadas en espejos, sea con los dispositivos creados por los artistas Thiago Trindade y Talita Procópio, o a través de los espejos colgados en los refugios junto a los portones de acceso al muelle.E,incluso, espiar por sobre el borde del muro, utilizando dispositivos construidos por los artistas, tales como:una silla de altura superior al muro de Deni Corsino, para contemplar el paisaje escondido del otro lado, o una escalera del artista Lucas Strey para subir junto al borde del muro,o, aún, captar vídeos e imágenes fotográficas a través del dispositivo tecnológico propuesto por el artista Pedro Ferraz.

Y, desde lo alto, por encima del muro, tal vez, sólo tal vez, este muro-monumento pueda ser entendido no como un objeto estático y permanente,sino como un objeto en el espacio que permite en algún sentido dejarse transformar permanentemente en tener-lugares (Didi-Hubermann, 2009), aunque su deseo de caída no sea así, tan explícito. Practicar sus bordes de dentro, de fuera y de arriba se hace necesario para aquellos que entienden las cidades como lugares poéticos.

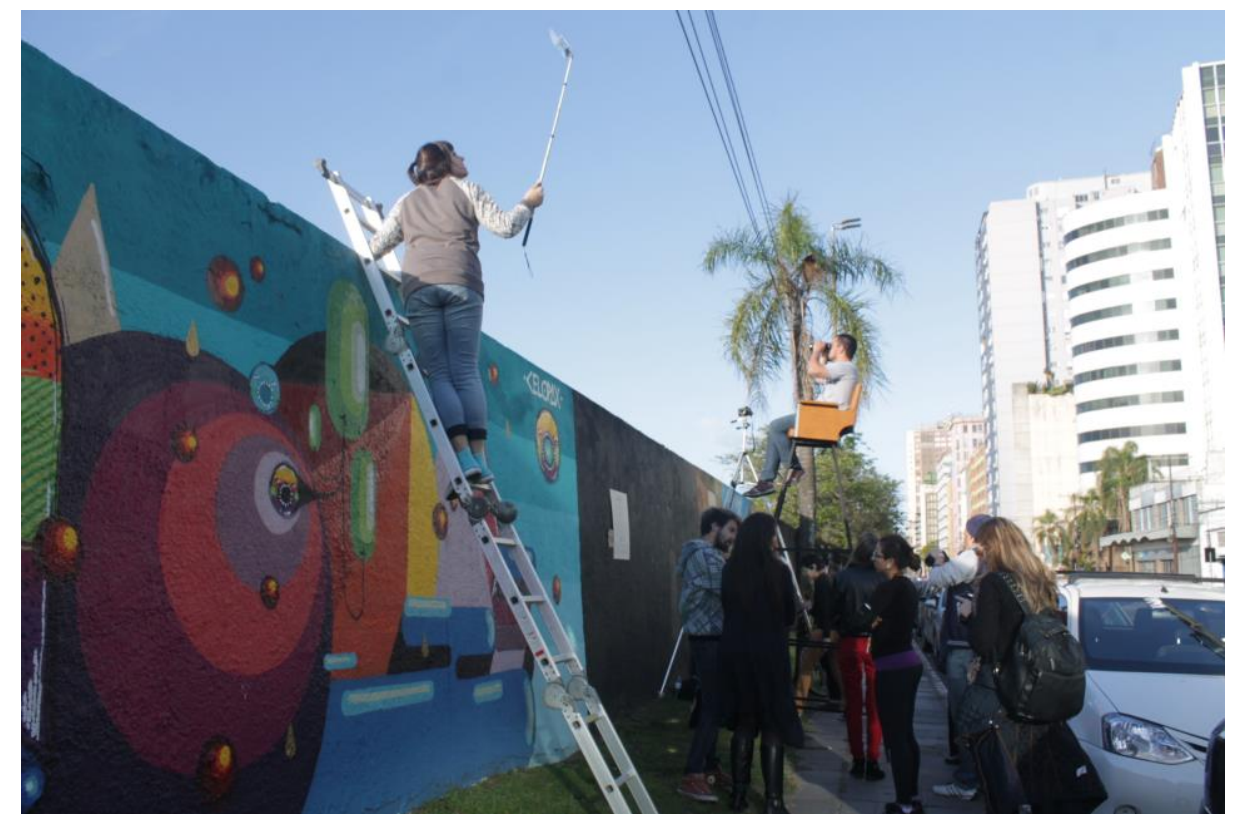

Figura 4- Espiação, 2016. Local: Muro da Av. Mauá, em Porto Alegre, RS-Brasil. Foto: Deni Corsino

\title{
APUNTES NO CONCLUSIVOS
}

Las andanzas practicadas (Jacques, 2012) en esta territorialidad ampliada del Muro de la av. Mauá en la ciudad de Porto Alegre, se extendieron en experiencias y percepciones tanto colectivas como individuales por parte de los artistas, precipitando nuevos significados y nuevas sospechas de este protagonista - el Muro de Mauá- y de sus interrelaciones con el medio y con el otro que habita la ciudad o permanece turista en su orilla.

El muro, en su negación, es no-lugar, es división, es límite visual y físico, es fisura y ruptura, porque es visible, espeso y encarnado. Al mismo tiempo no podemos olvidar que según Augé (2005, p.74), el no-lugar "nunca existe bajo una forma pura; lugares se recomponen en él; relaciones se reconstituyen en él", ya que lugar y no-lugar son ante todo polaridades huidizas, donde "el primero nunca se apaga completamente y el segundo nunca se realiza totalmente." El Muro de Mauá, se afirma como lugar del entre, lugar del abandono, de la protección y del alejamiento. Nos provoca curiosidad por ser lo que "es" y representar lo que "no está". 
Los artistas al acercarse a los muros intentan resignificarlos, no para justificarlos o incluso mantenerlos, sino para entender los motivos por los cuales estos son construidos, ampliados y mantenidos y, más, para poder hacerlos perder su permanencia opresiva o su función primera de segregación y alejamiento. Para Siza Vieira(2017), los muros que se quieren erguir actualmente no son arquitectura, sino, agresión y aislamiento y, en Brasil, lo que hace que estos suban y se proliferem es el miedo. Miedo de agresión, miedo de violencia, miedo de convivencia, miedo del otro y, así, nos aislamos en nuestros pequeños ficticios territorios. El Muro de Mauá, fue construido para proteger un territorio aterrado por miedo de la retomada de las aguas que allí tenían derecho de permanecer. Un miedo que intenta justificarse por la palabra protección. El miedo colectivo lo mantiene en pie, medio torcido, con fisuras y con rendijas. Tal vez la aproximación continuada pueda volverlo menos alto, menos espeso, menos opaco y el paisaje del otro lado del río pueda ser vivenciado por aquellos que andan a pie a la orilla de la ciudad de Porto Alegre en algún momento.

\section{FUENTES REFERENCIALES.}

AUGÉ, Marc. Não-Lugares: Introdução a uma antropologia da supermodernidade. Campinas, SP: Papirus, 2005 ISBN: 8530802918

BARACHINI. T. Em cima do muro: experiências da borda. In Cirillo, José, Org.; Grando, Ângela, Org.; Belo, Marcela, Org. Poéticas da Criação, E.S. 2016. Seminário Ibero-americano sobre o Processo de Criação nas Artes. Vitória, ES: PROEX/UFES, 2016 ISBN 9788565276306

CALDEIRA, Teresa. Muros novas tecnologias do público. IN Muntadas: informações, espaço, controle. [catálogo]. São Paulo:Pinacoteca do Estado, 2011, p.217-233 ISBN: 9788599117613

CANTON, Katia. Espaço e lugar. São Paulo: WMF Martins Fontes, 2009. ISBN: 9788578272272

DIDI-HUBERMAN, Georges. Ser Crânio: lugar, contato, pensamento, escultura. Belo Horizonte: C/Arte, 2009 ISBN: 8576540894

FOUCAULT, Michel. Estética, literatura e pintura, música e cinema. Rio de Janeiro, Forense Universitaria, 2009. ISBN:9788521803904

HARDT, Carlos apud Carriel, Paola. Muro na favela. Proteção ou segregação social? Jornal Gazeta do Povo. Rio de Janeiro: 04/04/2009. Acceso el : 10/03/2017. Disponible en: <http://www.gazetadopovo.com.br/vida-e-cidadania/muro-na-favela-protecaoou-segregacao-social-bih9sn9xh9q1jqwmjuxt14gum $>$

JACQUES, Paola Berenstein. Elogio aos errantes. Salvador: EDUFBA, 2012. ISBN: 9788523208707

XAVIER, Ágata. Siza Vieira: "Os muros [que se querem erguer] não são arquitectura, são agressão e isolamento" [Entrevista]. Jornal GPS. Lisboa, 06/03/2017. Acceso el : 10/03/2017 Disponible en: <http://www.sabado.pt/gps/detalhe/as-varias-visoes-de-alvaro-siza$\underline{\text { vieira> }}$

ZARANKIN, André. Corpos congelados: uma leitura metafórica de paredes e muros em Belo Horizonte, MG. In. Arqueologia na paisagem: novos valores, dilemas e instrumentais. Rio de Janeiro: Rio Book's, 2012. ISBN: 97885615562345 